\title{
AVANÇO DO SETOR SUCROALCOOLEIRO E EXPANSÃO DA FRONTEIRA AGRÍCOLA EM GOIÁS ${ }^{1}$
}

\author{
Adriana Aparecida Silva ${ }^{2}$, Fausto Miziara ${ }^{3}$
}

\section{ABSTRACT \\ SUCROALCOHOL SECTOR AND AGRICULTURAL FRONTIER EXPANSION IN THE GOIÁS STATE, BRAZIL}

The Brazilian territory occupation dynamics presents patterns defined by literature as "fronts". A previous process refers to an Agricultural Frontier characterized by the transformation movement towards its using form, based on new technologies implementation. This study aimed to understand the recent sugar cane expansion process in the Goiás State, Brazil, assuming that the sucroalcohol sector progress represents a new stage in the Agricultural Frontier expansion. Cartographic products, as well as data on sugar refineries supplied by the Brazilian Ministério da Agricultura, Pecuária e Abastecimento, which were manipulated with the aid of the GIS ArcMap 9.2 and statistically treated by the Excel's charts editor, were used. This study was based on the sugar cane expansion pattern representation between 2005 and 2010, besides the discussion on sugar refineries location, concerning their current spatial pattern. Finally, the soil use dynamics between 2002 and 2009, focusing on the sugar cane implementation areas, was evaluated. The data allowed to deduce that the Goiás State takes part in this new Agricultural Frontier expansion process, in which, opposing what is politically stated, the expansion occurs mainly on Savannah and consolidated agricultural areas towards a center-southeast axis, which represents the same Agricultural Frontier expansion in the 1970 's, especially with grains, particularly soybean.

KEY-WORDS: Sugar cane; spatial expansion, Savannah.

\section{INTRODUÇÃO}

Historicamente, o território brasileiro foi ocupado do litoral para o interior, e este processo de ocupação "sertão adentro" recebeu o nome de expansão de fronteiras (caracterizado por distintas "frentes") (Velho 1972, Martins 1996). Considera-se que este processo de ocupação caracterizou-se pelo pragmatismo e imediatismo, onde a preservação

\section{RESUMO}

A dinâmica de ocupação do território brasileiro apresenta padrões que a literatura define como "frentes". Um processo posterior a este refere-se à chamada Fronteira Agrícola, que se caracteriza pelo movimento de transformação na forma de uso, com base na inserção de novas tecnologias. Este trabalho buscou compreender o recente processo de expansão da cana em Goiás, partindo do pressuposto de que o avanço do setor sucroalcooleiro, neste Estado, representa uma nova etapa de expansão da Fronteira Agrícola. Foram utilizados produtos cartográficos, além de dados referentes a usinas, fornecidos pelo Ministério da Agricultura, Pecuária e Abastecimento, os quais foram manipulados com o auxílio do SIG ArcMap 9.2 e tratados estatisticamente com o editor de gráficos do Excel. O estudo baseou-se na representação do modelo de expansão da cana-de-açúcar, de 2005 a 2010, além de discussão acerca da localização de usinas, em relação ao padrão espacial que seguem. Por fim, discutiu-se a dinâmica de uso do solo, entre 2002 e 2009, com ênfase na inserção de áreas de produção da cana-de-açúcar. Os dados permitiram deduzir que o Estado de Goiás se insere neste novo processo de expansão de Fronteiras Agrícolas, no qual, ao contrário do que é defendido politicamente, a expansão ocorre principalmente em áreas de agricultura já consolidadas e de Cerrado, seguindo o eixo preferencial centro-sudoeste, que representa o mesmo do avanço da fronteira agrícola na década de 1970, sobretudo com grãos, em particular a soja.

PALAVRAS-CHAVE: Cana-de-açúcar; expansão espacial; Cerrado.

da vegetação original sempre esteve relegada a um segundo plano (Franco 1992).

Em Goiás, a agropecuária despontou como a base fundamental deste processo de instalação da Frente Pioneira (quando da ocupação inicial do território) e da Frente de Expansão (referente ao uso capitalista da terra), sobretudo a partir do início do Século XX, com a crescente intensificação da ocupação, bem como uma maior apropriação capitalista

1. Trabalho recebido em ago./2010 e aceito para publicação em set./2011 (n registro: PAT 11054/ DOI: 10.5216/pat.v41i3.11054).

2. Universidade Federal de Goiás, Instituto de Estudos Socioambientais, Goiânia, GO, Brasil. E-mail: ueg.adriana@gmail.com.

3. Universidade Federal de Goiás, Faculdade de Ciências Sociais, Goiânia, GO, Brasil.E-mail: fausto@fchf.ufg.br. 
da terra (Miziara 2009). Na região sul do Estado, por exemplo, houve uma intensificação da pecuária e inserção de uma agricultura voltada para o mercado. Já na região norte, houve uma ocupação desordenada e predatória, que teve como motivação principal a expansão rodoviária, principalmente com a instalação da Belém-Brasília. Este período, em geral, foi marcado por uma ocupação de fronteiras goianas por não goianos, como é o exemplo da Colônia Agrícola Nacional de Ceres (IPEA 2001), e, em alguns casos, por não brasileiros (Chaul 1992).

Em meados da década de 1970, teve início o processo chamado de "Expansão da Fronteira Agrícola", onde se destaca a ação estatal, a qual busca a expansão da moderna tecnologia agrícola no Cerrado (Oliveira 1997). Contempladas nos Planos Nacionais de Desenvolvimento (PNDs), estas ações pretendiam re-estruturar o território, com a inserção de infraestrutura econômica e incentivo ao aumento da produção agropecuária. Neste contexto, Goiás já era considerado importante fronteira agrícola a se ocupar, uma vez que tal lógica segue os padrões de "natureza privilegiada", ou seja, clima ameno, fertilidade natural das terras, facilidades de transporte via navegação (Goiás é uma região de cumeeira, onde estão as nascentes de três grandes bacias hidrográficas), além de riquezas minerais, que, ao longo da história, mostraram-se como grande elemento potencializador para a expansão (WWF 2000).

Nesse sentido, segundo Miziara (2005), concordando com o World Wildlife Fund (2000), a partir de 1975, a expansão horizontal, que promove a ocupação das terras, é substituída por uma maior exploração dos solos já ocupados, caracterizando um novo momento da expansão de fronteira agrícola, principalmente nos Estados de Goiás, Mato Grosso, Minas Gerais e Maranhão, sendo a soja a principal commodity propulsora deste novo processo.

O termo expansão de fronteira é entendido, de acordo com Martins (1997), como definidor da modalidade de desenvolvimento capitalista, ou seja, processo que representa o momento histórico de alteração das realidades de uso espacial da terra. Tal modelo de expansão de fronteira se efetiva, de fato, após a implantação dos Programas de Desenvolvimento Agrícola voltados para a área dos Cerrados, sendo que esta ocupação se dá em áreas com melhor infraestrutura, condições topográficas favoráveis à mecanização e proximidade a jazidas de calcário (WWF 2000).
Diante do exposto, o histórico de ocupação da região dos Cerrados, em específico do território goiano, evidencia uma sobreposição de diversos processos de expansão, primeiramente o da pecuária, seguido da agricultura. Vale lembrar que a agricultura não eliminou a pecuária, mas, ao contrário, modernizou-a, tendo sido iniciada pela ocupação propriamente dita das terras, obedecendo à sequência de inserção destas na estrutura de mercado capitalista, e seguida pelos processos de re-estruturação, na forma de uso e ocupação. Historicamente, foi a estrutura de mercado que exigiu uma constante transformação ou readequação das fronteiras agrícolas em Goiás, além de sua expansão para os Estados vizinhos, em áreas de Cerrado e Pantanal.

Ao trazer a ideia de expansão de fronteira agrícola para o momento histórico contemporâneo, em Goiás, vivenciado pela expansão da cana-de-açúcar, de acordo com Miziara (2009), não seria correto utilizar, hoje, este conceito, no sentido de ocupação de novas áreas, mesmo porque não existem terras devolutas na região. Tal conceito é pertinente, no que diz respeito à expansão da moderna tecnologia e à utilização mais intensiva do solo, o que não necessariamente viria acompanhado de desmatamento. Para fundamentar sua tese, o autor apresenta o conceito de renda fundiária proposto por Marx, no Século XIX, que entende que o meio de produção fundamental na agricultura (a terra), por não ser homogêneo, torna-se passível de apresentar resultados diferenciados aos capitais investidos. Assim, há uma forte articulação entre as características "naturais" da terra (fertilidade, topografia e localização) e os investimentos realizados pelos capitalistas.

Miziara (2009), seguindo os conceitos de Marx, afirma que existe uma forte relação entre a Renda Diferencial I e a Renda Diferencial II. Em outras palavras, os capitalistas procuram intensificar os investimentos (associados à Renda Diferencial I) nas regiões que consideram mais propícias, devido às suas características naturais, e, com isto, o padrão tecnológico (associado à Renda Diferencial II) modifica-se mais rapidamente, nestas regiões.

Em Goiás, existe o exemplo do município de Rio Verde, localizado na porção sul do Estado, região plana e de solos férteis, onde a agricultura se desenvolveu com bases comerciais, ainda no fim do Século XIX, sendo influenciado por Minas Gerais e São Paulo. Neste sentido, o termo expansão de fronteiras agrícolas, atualmente, refere-se às modificações 
na forma de uso, ocupação e implementação de tecnologia na terra. No caso específico da expansão da cana-de-açúcar, esta mudança no padrão tecnológico, associada a um maior investimento (portanto Renda Diferencial II), pode ser observada, pelo fato de o custo de investimento da cana-de-açúcar ser 2,5 vezes o custo da soja, por exemplo (Miziara 2009).

No que se refere à tendência de expansão da cana-de-açúcar, em 2006, foi lançado, pelo Ministério da Agricultura, Pecuária e Abastecimento, o Plano Nacional de Agroenergia 2006-2011 (Brasil 2006). Tal plano busca apontar regiões consideradas propícias à expansão da agricultura voltada para a produção de energia, agregando cadeias produtivas a ela ligadas, tendo como foco a interiorização e regionalização do desenvolvimento, onde seriam privilegiadas as regiões menos desenvolvidas.

Goiás é considerado área potencial para expansão do cultivo da cana-de-açúcar, apresentando-se como apto para a nova configuração da Fronteira Agrícola, onde o foco é a re-estruturação da produção e inserção de novas tecnologias, em busca de maior lucratividade. O discurso oficial, tanto por parte dos agentes do Estado, quanto dos produtores, ressalta a possibilidade de expansão das lavouras de cana-de-açúcar em áreas de pastagem degradada, sem, contudo, implicar em ameaças maiores à vegetação nativa ou à produção de alimentos. A Embrapa (2009), em seu Zoneamento Agroecológico da Cana-de-açúcar para o Brasil, com recorte para Goiás, na escala 1:1.000.000, evidencia este Estado como região de média a alta aptidão agrícola, onde ocorreria a substituição de áreas atualmente utilizadas predominantemente por pastagens, principalmente na porção sudoeste e central. Castro et al. (2007), entretanto, trabalhando na escala 1:500.000, já enfatizavam a possibilidade de conversão de áreas agrícolas e de novos desmatamentos, comparando-as, em relação à localização das usinas instaladas, aprovadas, em construção e as que estavam em processo de licenciamento ambiental, com o Mapa de Uso do Solo do Estado de Goiás relativo ao ano de 2002, segundo o qual as usinas estariam predominantemente em áreas de agricultura.

O objetivo deste estudo foi analisar as áreas de expansão recente da cana-de-açúcar em Goiás, buscando identificar a tendência de expansão e de competição que irá se estabelecer entre esta cultura e as demais áreas antropizadas, e mesmo com os remanescentes de vegetação. Para tanto, foram uti- lizados dados cartográficos produzidos pelo Canasat do Instituto Nacional de Pesquisas Espaciais, produto cartográfico de uso da terra do Probio e produto cartográfico representativo dos polígonos da cana-de-açúcar disponibilizado pela Secretaria da Fazenda de Goiás, além de dados do Ministério da Agricultura Pecuária e Abastecimento, relativos à localização e data de registro das usinas.

Os procedimentos de análise envolveram a ferramenta de geoprocessamento ArcMap 9.2, para cruzamento e geração de mapas, além do editor de gráficos do programa Excel. Os resultados foram apresentados em três seções de discussões, com as seguintes temáticas: 1) A expansão da área de cultivo da cana-de-açúcar em Goiás: o avanço do setor sucroalcooleiro; 2) A nova expansão da fronteira agrícola, em relação à dinâmica de expansão e de distribuição das usinas; 3) A nova expansão da fronteira agrícola, em relação às mudanças na forma de uso e ocupação da terra.

\section{A EXPANSÃO DA ÁREA DE CULTIVO DA CANA-DE-AÇÚCAR EM GOIÁS: O AVANÇO DO SETOR SUCROALCOOLEIRO}

A evolução histórica da produção de cana-de-açúcar no Brasil, entre 1932 e 2005, apresenta um aumento na produção, após o ano de 1942, seguido por crescimento pouco representativo até 1970, quando ocorre grande crescimento na área de produção, até 1987 (IBGE 2009). Este período é seguido por uma estagnação, e mesmo uma queda, em 1993, havendo um novo momento de crescimento, a partir de 2002, até o período atual. Vários foram os fatores que possibilitaram a produção da cana-de-açúcar no Brasil, dentre eles a existência de solo e clima favoráveis ao cultivo, além de o açúcar ser um produto muito bem cotado no comércio internacional, tendo sido base econômica, entre os Séculos XVI e XVII (Castro 2004).

Criado pelo Ministério da Agricultura, Pecuária e Abastecimento, o Ementário Nacional da Agroindústria apresenta uma cronologia da legislação agroindustrial canavieira, com destaque para três decretos e leis que apresentam maior relevância para a identificação do histórico da cana, no Brasil: a) 1942, com a declaração da Indústria Alcooleira como sendo de interesse nacional, o que vai culminar em um incentivo à produção empresarial da cana-de-açúcar; b) 1975 , quando foi instituído o Programa Nacional 
do Álcool (Proálcool), após a crise do petróleo de 1973 e do açúcar de 1975, crises que representaram intensas quedas nos preços, no mercado internacional, fato que levou os usineiros a reivindicarem, do Governo Federal, a instituição deste Programa, que traria incentivos para a concretização da agricultura energética no País, levando o Brasil a apresentar destaque na produção de combustível alternativo (Santos 1987); c) 1993, com a regulamentação do percentual de mistura carburante automotiva, garantindo mercado para a indústria da cana-de-açúcar, a qual ganha nova impulsão, com a produção de veículos de motor bicombustível.

Atualmente, em virtude da diminuição de jazidas de petróleo, e mesmo pela crise ambiental, na qual se sabe que a emissão de gases tóxicos dos motores de veículos automotivos estaria contribuindo para o aquecimento global, é crescente o investimento e o incentivo ao plantio da cana-de-açúcar, objetivando-se a produção de etanol. Este incremento deve ocorrer em terras consideradas inexploradas, como as dos Cerrados de Goiás, Minas Gerais, Mato Grosso e Amazônia (Pasquatelo \& Zito 2000), com prioridade de ocupação para áreas degradadas, conforme publicado no Programa Nacional de Agroenergia 2006-2011 (Brasil 2006).

No entanto, a história da cana-de-açúcar em Goiás não é recente, pois, já em 1935, existiam, nos municípios goianos, cerca de 1.400 engenhos. De acordo com levantamentos do Censo Agropecuário de 1940/1975, na safra de 1940, houve produção de 166.833 toneladas (Santos 1987), números, estes, crescentes ano a ano, chegando, em 1984, a uma safra de 3.644.846 toneladas de cana-de-açúcar, com avanço para 5.163.596 toneladas, em 1988. Tal produção foi seguida de uma queda, entre os anos de 1989 e 1995. Daí em diante, houve novo crescimento, com maior impulso, alcançando, na safra de 1996, uma produção de 6.474 .564 toneladas, chegando a 16.140.042, em 2007 (IBGE 2009). Tais dados podem ser completados com valores da safra 2007/2008, de 19,85 milhões de toneladas, e safra 2008/2009, com produção de 29,39 milhões de toneladas, valores que posicionam Goiás em quarto lugar, em termos de área plantada, sendo suplantado apenas por São Paulo, Minas Gerais e Paraná (IBGE 2009).

De acordo com os dados da Secretaria de Planejamento do Estado de Goiás (Goiás 2009), a produção de cana-de-açúcar situa-se, atualmente, em primeiro lugar no ranking do Estado e de todo o
Centro-Oeste, ficando a soja como segunda principal produção. Em relação à produção em toneladas, a expansão da cana-de-açúcar ocorre de forma bastante acentuada, principalmente a partir de 2007, em Goiás (Figura 1), assim como na mesorregião sul goiano, que se apresenta como área de tendência de expansão (Figura 2). Em termos de incremento de área para a produção, verifica-se que, em Goiás, houve, para produção de cana-de-açúcar, entre 2000 e 2009, aumento de cerca de $372 \%$ em áreas, sendo que, para a soja, o incremento foi da ordem de $155 \%$, para o mesmo período. O mesmo ocorre para a mesorregião sul goiano, onde o incremento de área, neste período, para a produção de cana-de-açúcar, foi da ordem de $432 \%$ e, para a soja, de $139 \%$. Tais dados reafirmam a tese de que existem mudanças no padrão agrícola do Estado, as quais refletem sobre a dinâmica do espaço agrícola.

Uma questão importante sobre a expansão do setor sucroalcooleiro diz respeito ao seu financiamento: trata-se de uma combinação de investimentos privados, financiamento direto do Estado (principal-

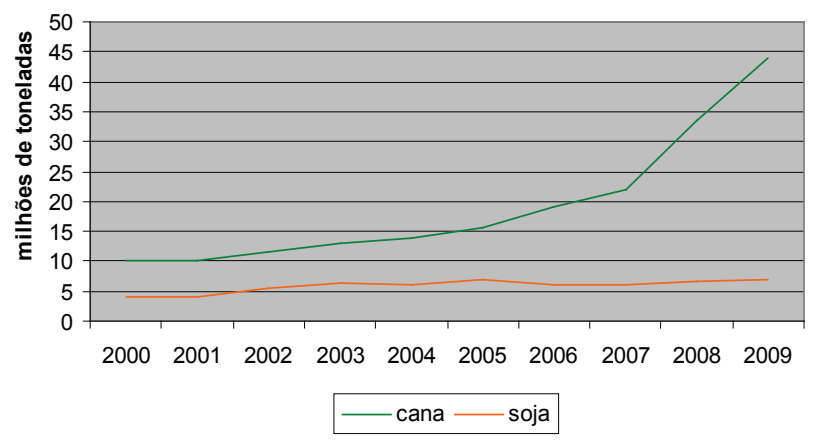

Figura 1. Evolução da produção de cana-de-açúcar e da soja em Goiás, entre 2000 e 2009.

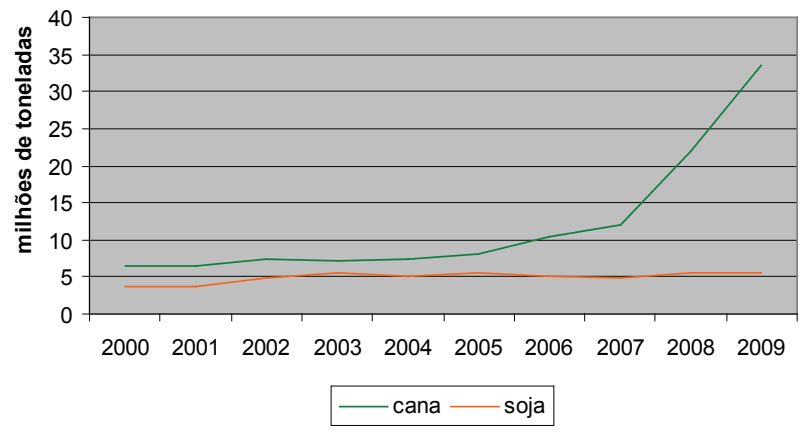

Figura 2. Evolução da produção de cana-de-açúcar e da soja, na mesorregião sul goiano, entre 2000 e 2009. 
mente recursos do Banco Nacional do Desenvolvimento - BNDES) e indireto, por meio de renúncia fiscal. Pelos dados da Tabela 1, é possível verificar que, entre 2004 e 2008, o volume de recursos do BNDES, para o setor sucroalcooleiro, aumentou 4,4 vezes, e a participação relativa do setor evoluiu de $1,24 \%$ para $5,64 \%$ do total de recursos emprestados.

Mais interessante que observar a evolução dos recursos alocados pelo BNDES é verificar a espacialização dos mesmos (Figura 3), onde é possível verificar a forte concentração de recursos em novas áreas de expansão da cultura da cana-de-açúcar.

Com a finalidade de se discutir a expansão da área de cultivo da cana-de-açúcar em Goiás, foram obtidos dados junto ao Canasat, uma base de dados espaciais do Instituto Nacional de Pesquisas Espaciais (2010), disponibilizada via Internet, relativos a uma série de imagens referentes às áreas com cultivo de cana-de-açúcar, nas safras 2005/2006, 2006/2007, 2007/2008, 2008/2009 e 2009/2010. Com base nestes produtos e com o auxílio do programa ArcMap 9.2, foi realizado o mapeamento dos polígonos da cana-de-açúcar (safra 2005 a 2010), onde realizou-se análise da dinâmica espacial, além de se estabelecer os novos eixos de expansão e as direções de tendência de inserção de novas áreas, para o cultivo da cana-de-açúcar em Goiás (Figura 4).

Observa-se que as áreas de cultivo da cana-de-açúcar se mantiveram situadas, preferencialmente, ao longo do eixo norte-sul do Estado, tendo expressiva expansão, a partir da safra 2008/2009, na porção sul, sendo que, a partir daí, o incremento de novas áreas vem acontecendo na região sudoeste do Estado. Como esta região é bastante utilizada pela agricultura, considera-se a hipótese de que a expansão da cana-de-açúcar se dê em substituição a outras culturas, no caso, a expectativa é que seja sobre áreas antes destinadas à produção da soja (Castro et al. 2007). Para verificar tal hipótese, é necessária uma análise específica da expansão, considerando-se a espacialização das usinas e o uso anterior da terra.

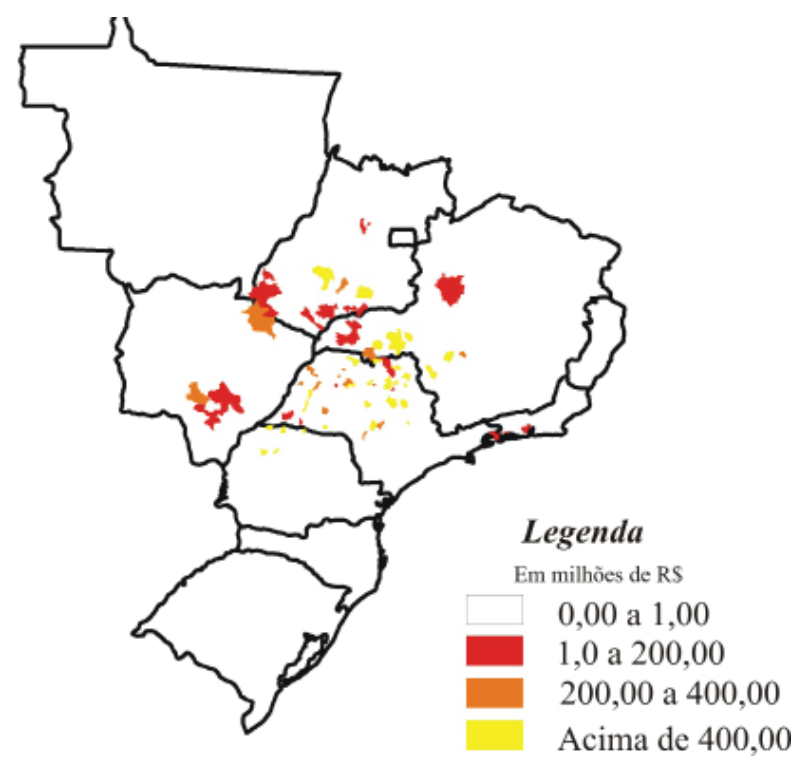

Figura 3. Distribuição geográfica dos investimentos apresentados ao Departamento de Biocombustíveis do BNDES (em milhões de R\$). Fonte: adaptado de Milanez (2008).

\section{NOVA EXPANSÃO DA FRONTEIRA AGRÍCOLA: DINÂMICA DE EXPANSÃO E DE DISTRIBUIÇÃO DAS USINAS}

O aumento na área plantada certamente tem relação direta com o aumento no número de usinas para produção de álcool e açúcar, em Goiás. Neste sentido, o processo de expansão agrícola está fortemente relacionado com as características físicas e de infraestrutura do espaço a ser ocupado. No caso específico das novas usinas, é necessária infraestrutura adequada para o escoamento da produção, além de matéria-prima disponível para o processamento. A matéria-prima não pode ser produzida muito distante da usina, ou mesmo sem vias de fácil acesso, pois a cana-de-açúcar possui apenas oito meses por ano para ser colhida e não pode ser estocada, além do curto prazo de 72 horas, desde sua colheita até o recebimento na indústria, a fim de se evitarem perdas

Tabela 1. Recursos do BNDES para o setor sucroalcooleiro, entre os anos de 2004 e 2008.

\begin{tabular}{lcrrrr}
\hline \multicolumn{1}{c}{ Desembolsos } & 2004 & 2005 & 2006 & 2007 & 2008 \\
\hline & & & R \$ milhões & & \\
Setor sucroalcooleiro & 604,93 & $1.098,29$ & $1.975,80$ & $3.592,44$ & $2.680,25$ \\
Todos os Setores & $48.716,60$ & $51.084,94$ & $55.471,60$ & $75.491,71$ & $47.530,29$ \\
\hline Participação do setor sucroalcooleiro & $1,24 \%$ & $2,15 \%$ & $3,56 \%$ & $4,76 \%$ & $5,64 \%$ \\
\hline Fonte: Milanez (2008). & & & &
\end{tabular}




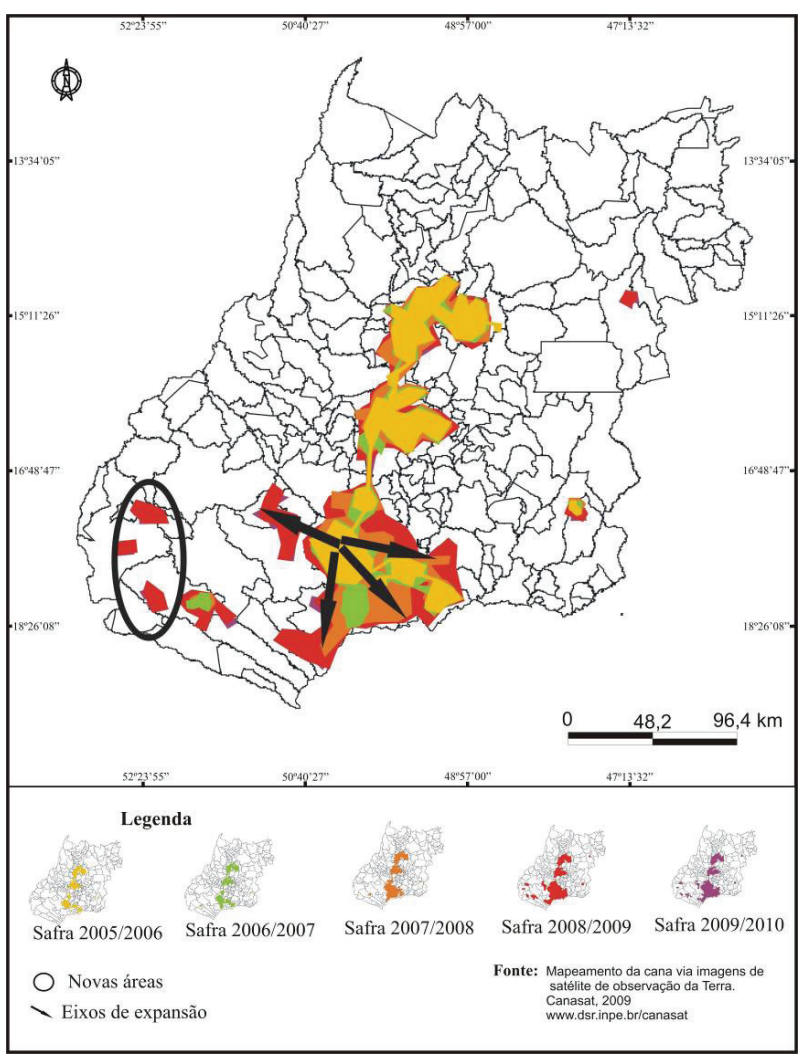

Figura 4. Eixos de expansão da área de cultivo da cana-de-açúcar em Goiás.

de qualidade, pela ação de bactérias e fermentação (Unica 2007).

Existem, em Goiás, de acordo com o Ministério da Agricultura, Pecuária e Abastecimento (Brasil 2006), trinta e uma usinas, ou unidades processadoras de cana-de-açúcar, devidamente registradas no Departamento de Cana-de-açúcar e Agroenergia deste Ministério (dados do dia 19 de junho de 2009). Tais unidades estão distribuídas em vinte e sete municípios, dos quais apenas Goianésia, Goiatuba, Itumbiara e Quirinópolis possuem duas unidades locadas em seu território. Considerando-se a distribuição das usinas por ano de registro, com referência à sua área de influência, a qual foi localizada e mapeada pela ferramenta de geoprocessamento ArcMap 9.2, foi possível realizar uma análise espaço-temporal do processo de expansão das usinas de cana-de-açúcar, no Estado de Goiás (Figura 5).

Desde 2002, existem usinas registradas em Goiás. Estas, no entanto, encontram-se concentradas na região central, denominada de "mato grosso goiano", área que foi ocupada no momento de expansão inicial do Estado. Deste período em diante, as usinas, principalmente entre 2006 e 2007, se inseriram no eixo norte/sul do Estado, muito provavelmente em virtude da localização das vias de escoamento da produção, principalmente as BRs 153, 060, 364 e 452 (Castro et al. 2007). Nos anos de 2006 e 2008, houve um maior número de registro de usinas, sendo que, especialmente em 2008, é possível correlacionar este fato à inserção de novas áreas de cultivo de cana-de-açúcar, conforme observado na Figura 3.

Recentemente, no entanto, a distribuição das usinas toma um novo direcionamento, com forte tendência para a ocupação da região sudoeste do Estado, dado que contribui para fortalecer a ideia de um novo impulso na expansão de Fronteiras Agrícolas, onde pode-se perceber que as terras do sudoeste já ocupadas pela agricultura passam a presenciar uma disputa entre a cultura de grãos e da cana-de-açúcar. Voltando ao modelo teórico proposto inicialmente, observa-se a evidência de que a mudança no uso está relacionada com a mudança do padrão tecnológico, o qual reflete, diretamente, no índice de investimento (Renda Diferencial II), uma vez que a cana-de-açúcar exige investimento maior do que outras culturas, como, por exemplo, a soja.

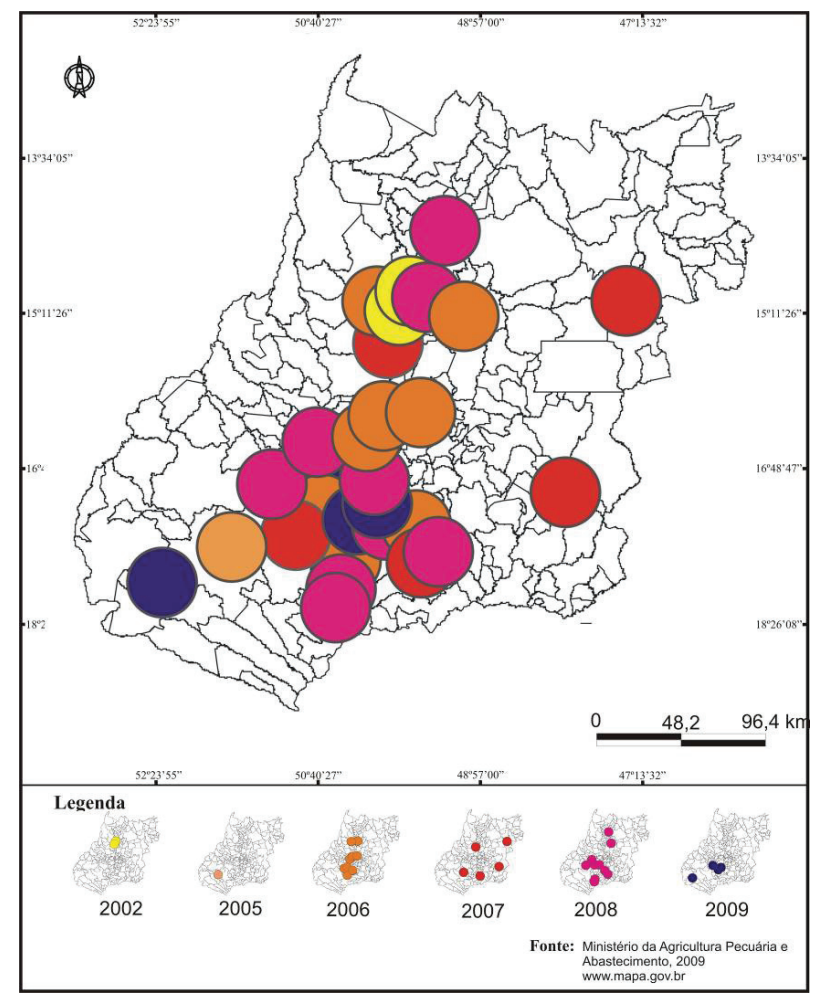

Figura 5. Distribuição das usinas, por ano de registro, junto ao Ministério da Agricultura, Pecuária e Abastecimento. 


\section{NOVA EXPANSÃO DA FRONTEIRA AGRÍCOLA: MUDANÇAS NA FORMA DE USO E OCUPAÇÃ̃O DA TERRA}

Para analisar o processo de inserção da cana-de-açúcar e das mudanças nas formas de uso do solo, foi realizado o cruzamento de informações sobre o uso do solo em 2002, momento em que o cultivo de cana-de-açúcar não era referência no Estado, com o produto de 2009, que apresenta a espacialização das áreas de produção de cana-de-açúcar. Os produtos utilizados foram: mapa do Projeto de Conservação e Utilização Sustentável da Diversidade Biológica Brasileira (Probio), de 2002, e Mapa das Áreas de Cultivo de Cana-de-açúcar, disponibilizado pela Secretaria da Fazenda do Estado de Goiás, referente aos dados disponíveis em agosto de 2009. Tais produtos foram manipulados em ambiente de SIG, com o auxílio da ferramenta ArcMap 9.2, e os dados tabulados em programa de edição de gráficos do Excel.

Para cada uma das trinta e uma usinas no Estado, foi associado um polígono, com raio de $40 \mathrm{~km}$, sendo que este valor representa uma tentativa de se dimensionar a área de influência da usina, uma vez que a legislação propõe a diversificação de culturas, em prol da segurança alimentar, conforme a Lei 4.244/08 (Repórter Brasil 2009). Para o mapeamento, foram criados shapes com os temas Cerrado, pecuária, agricultura e cana-de-açúcar; dimensionada a área de influência das usinas; e inseridos nesta os recortes dos polígonos das classes. Em seguida, foi feito o cálculo da área, em hectares, dos polígonos de uso mapeados e realizada a sobreposição dos temas uso (2002) x cana (2009). Uma observação importante diz respeito ao mapeamento na porção sul do Estado, onde foram contempladas áreas de não Cerrado, que se referem, originalmente, às áreas de Mata Atlântica, segundo o IBGE (2010). Tais áreas, no entanto, também foram considerados na tabulação dos resultados. O mapeamento das trinta e uma usinas culminou no mapa de "Uso do solo por raio de $40 \mathrm{~km}$ das usinas" (Figura 6).

Ao longo do período selecionado (2002 a 2009), houve uma notável mudança na forma de uso da terra, principalmente se considerado que, em 2002, a área de cultivo da cana-de-açúcar estava restrita a uma pequena porção, na região central do Estado. Já em 2009, a área de cana-de-açúcar observada dentro do raio de influência das usinas revela incremento de $1.405 .878 \mathrm{ha}$, correspondentes a uma

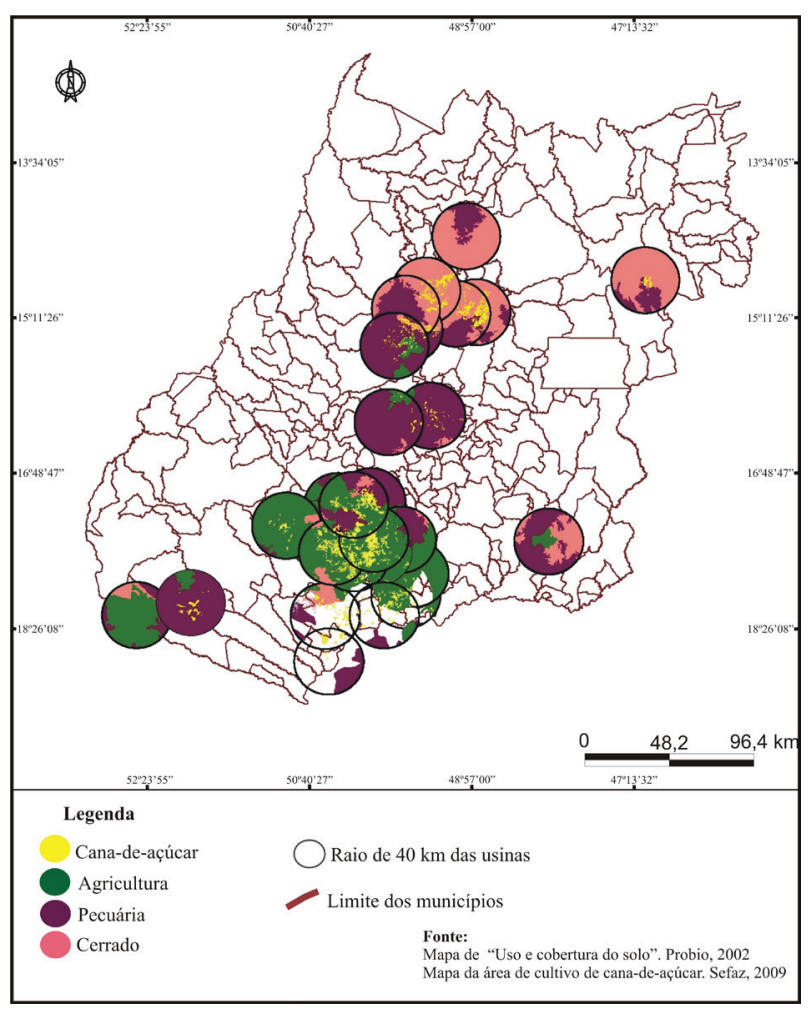

Figura 6. Uso do solo em Goiás, nas áreas das usinas de canade-açúcar.

alteração em $8 \%$ do total das áreas analisadas, em período de sete anos (Figura 7). Com área de maior abrangência, observa-se o uso referente à agricultura (39\%), seguida da pecuária (27\%), Cerrado (16\%) e não Cerrado (10\%).

Em relação à área ocupada com outras formas de uso, a qual perde lugar para o cultivo da cana-de-açúcar, no raio de abrangência de cada usina, entre 2002 e 2009, a agricultura aparece em primeiro lugar, com 14,38\% em perda de área, seguida pelas áreas de Cerrado (7,69\%), não Cerrado (porção sul

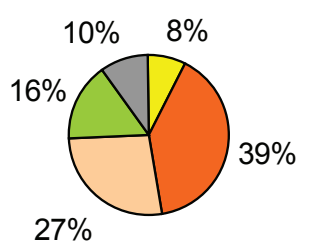

$\square$ cana $\square$ agricultura $\square$ pecuária $\square$ cerrado $\square$ não cerrado

Figura 7. Dados médios referentes aos tipos de uso da terra, em áreas relativas a um raio de $40 \mathrm{~km}$ ao redor das usinas. 
do Estado, com 4,81\%) e, por fim, de pecuária, com $3,67 \%$ (Figura 8).

Considerando-se apenas as áreas onde o cultivo da cana-de-açúcar foi efetivado, pôde-se confirmar a ideia de substituição de culturas praticadas em 2002, uma vez que $67 \%$ destas áreas, atualmente ocupadas por cana-de-açúcar, eram, então, destinadas à agricultura, antes da expansão recente do setor sucroalcooleiro. No que diz respeito ao avanço da cana-de-açúcar sobre áreas de vegetação nativa, um fato preocupante, do ponto de vista ambiental, é que $15 \%$ se deu em área de Cerrado e $6 \%$ em outro tipo de vegetação. Por fim, apenas $12 \%$ da expansão da cana-de-açúcar de fato ocorre em áreas de pecuária, dado que contradiz, fortemente, o discurso oficial, onde as áreas prioritárias, a serem incorporadas à nova atividade, seriam as pastagens degradadas.

Considerando-se o exposto, não há motivos para supor que a expansão da cana-de-açúcar esteja ocorrendo efetivamente em áreas de pastagem degradada, como informa o discurso oficial, pelo menos não enquanto esta opção ficar a cargo dos mecanismos livres de mercado e não houver um marco regulatório. No sentido teórico, a interpretação do processo recente de expansão da cana-de-açúcar pode ser compreendida como uma nova etapa da expansão da fronteira agrícola (Miziara 2009), inclusive reproduzindo muito da dinâmica anterior. Neste caso, seria de se esperar (como efetivamente foi constatado) uma competição da cana-de-açúcar com as culturas já instaladas, principalmente a soja. A cana-de-açúcar apresenta potencial para substituir a soja em diversas regiões, por se tratar de uma cultura com nível de investimento mais elevado, o que configura mudança significativa no padrão tecnológico.

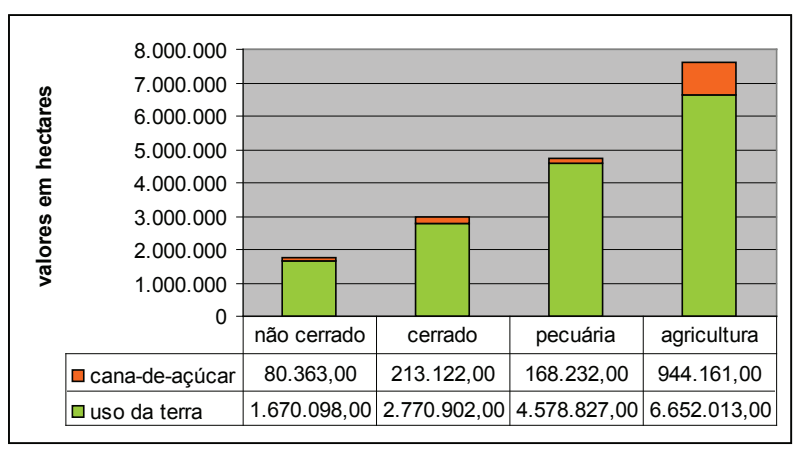

Figura 8. Área ocupada com cana-de-açúcar e usos da terra.

\section{CONSIDERAÇÕES FINAIS}

Os dados referentes à expansão recente da cana-de-açúcar, em Goiás, permitem constatar dois movimentos combinados. Em primeiro lugar, a expansão se dá a partir das áreas historicamente ocupadas pelas culturas, ou seja, temos muito mais um sentido de continuidade que de ruptura, na ocupação de novos espaços. Em segundo lugar, a expansão tende a reproduzir um movimento de expansão da fronteira agrícola, como observado nos anos 1980, quando a soja desempenhou papel de cultura dinâmica. Com isto, pôde-se constatar uma competição de áreas entre a cana-de-açúcar e as culturas já instaladas, principalmente a soja. Cabe ressaltar que os mesmos fatores que tornaram o Estado atraente para a primeira expansão da fronteira agrícola, nos anos 1970/1980, manifestam-se claramente na presente expansão da cana-de-açúcar.

A combinação de terras mais baratas que nas áreas de ocupação tradicional da cultura (principalmente quando comparada a São Paulo), topografia adequada, infraestrutura e distância dos principais mercados consumidores, além da riqueza em recursos hídricos, faz com que Goiás e, em menor escala, outros Estados do Centro-Oeste, se apresente como "área potencial" para uma nova expansão da fronteira agrícola, tal como reconhece o Plano de Agroenergia do Governo Federal (Brasil 2006). Neste sentido, um recente trabalho da Embrapa (2009) privilegia o Estado de Goiás como referência, em termos de aptidão agroecológica, para o cultivo desta gramínea, assim como trabalhos publicados pela Unica (2007) e Unicamp (2005), que indicaram que cerca de 50\% da área do Estado apresenta aptidão para o cultivo da cana-de-açúcar, integrando, com o Mato Grosso do Sul, parte do Mato Grosso e o Triângulo Mineiro, o chamado "polígono da cana" (Martino 2008).

Tais mudanças, ainda que benéficas, do ponto de vista econômico, pela inserção do Estado em diversos programas de incentivo à produção, geração de emprego e, sobretudo, renda, podem ocasionar problemas de outra natureza, como forçar o deslocamento dos produtores de soja e pecuaristas para o norte, rumo à Amazônia, sendo, portanto, causadora indireta de novos desmatamentos. Por fim, a substituição de áreas de vegetação natural por áreas de cultivo, conforme apresentado neste estudo, pode trazer prejuízos ambientais incalculáveis, além de outros impactos causados pelo uso de agrotóxicos e 
irrigação, que podem significar geração de passivos ambientais futuros.

A questão que se apresenta às novas investigações é: uma vez reconhecida a tendência de expansão da cana-de-açúcar, quais os possíveis impactos ambientais e sociais deste processo?

\section{REFERÊNCIAS}

BRASIL. Ministério da Agricultura, Pecuária e Abastecimento. Secretaria de Produção e Agroenergia. Plano nacional de agroenergia 2006-2011. 2. ed. rev. Brasília, DF: Embrapa Informação Tecnológica, 2006.

CASTRO, J. A. de. O Estado e a apropriação do território de Goiás. In: GOMES, H. O espaço goiano: abordagens geográficas. Goiânia: AGB, 2004. p. 59-92.

CASTRO, S. S. de et al. Estudo da expansão da cana-deaçúcar no Estado de Goiás: subsídios para uma avaliação do potencial de impactos ambientais. In: FÓRUM DE CIÊNCIA \& TECNOLOGIA NO CERRADO, 2., 2007, Goiânia. Anais... Goiânia: SBPC, 2007. p. 9-17.

CHAUL, N. F. Marcha para o oeste. In: SILVA, L. S. D. da (Org.). Relações cidade-campo: fronteiras. Goiânia: Ed. da UFG, 1992. p. 113-128.

EMPRESA BRASILEIRA DE PESQUISA AGROPECUÁRIA(Embrapa). Zoneamento agroecológico da cana-de-açúcar. 2009. Disponível em: <http://www. cnps.embrapa.br/zoneamento_cana_de_acucar/ $>$. Acesso em: 27 set. 2009.

FRANCO, J. L. A. Natureza no Brasil: ideias, políticas, fronteiras (1930 a 1992). In: SILVA, L. S. D. da (Org.). Relações cidade-campo: fronteiras. Goiânia: Ed. da UFG, 1992. p. 129-143.

GOIÁS (Estado). Secretaria Estadual de Planejamento. Centro-Oeste e Brasil: ranking da produção dos principais produtos agrícolas 2008/2009. 2009. Disponível em: $<\mathrm{http}$ ://www.seplan.go.gov.br/>. Acesso em: 13 out. 2009.

INSTITUTO BRASILEIRO DE GEOGRAFIA E ESTATÍSTICA (IBGE). Anuário estatístico do Brasil: 1937-1987; CEPAGRO 1988-1992; LSPA 1993-2005. 2009. Disponível em: <http://www.ibge.gov.br>. Acesso em: 15 set. 2009.

INSTITUTO BRASILEIRO DE GEOGRAFIA E ESTATÍSTICA (IBGE). Mapa de vegetação do Brasil. 2010. Disponível em: <http://www.ibge.gov.br/home/ presidencia/noticias/>. Acesso em: 14 jan. 2010.

INSTITUTO DE PESQUISA ECONÔMICAAPLICADA (IPEA). Caracterização das tendências da rede urbana do Brasil: redes urbanas regionais: Norte, Nordeste e CentroOeste. Brasília, DF: IPEA, 2001.

INSTITUTO NACIONAL DE PESQUISAS ESPACIAIS (INPE). Mapeamento da cana via imagens de satélite de observação da Terra: Canasat. 2010. Disponível em: $<$ http://www.dsr.inpe.br/mapdsr/frame.jsp>. Acesso em: 14 jan. 2010.
MARTINO, V. de. O novo ciclo da cana. Veja, São Paulo, jul. 2008. Opnião. Disponível em: $<$ http://veja.abril.com. br/>. Acesso em: 23 jul. 2008.

MARTINS, J. de S. A reprodução do capital na frente pioneira e o renascimento da escravidão. In: MARTINS, J. de S. Fronteira: a degradação do outro nos confins do humano. São Paulo: Hucitec, 1997. p. 143-203.

MARTINS, J. de S. O tempo da fronteira: retorno à controvérsia sobre o tempo histórico da frente de expansão e da frente pioneira. Tempo Social, São Paulo, n. 8, p. 2570, maio 1996.

MILANEZ, A. Y.; BARROS, N. R.; FAVERET FILHO, P. de S. C. O perfil do apoio do BNDES ao setor sucroalcooleiro. BNDES Setorial, Rio de Janeiro, n. 28, p. 3-36, set. 2008.

MIZIARA, F. Expansão da lavoura de cana em Goiás e impactos ambientais. In: CONGRESSO BRASILEIRO DE SOCIOLOGIA, 14., 2009, Rio de Janeiro. Anais... Rio de Janeiro: UFRJ, 2009. p. 1.

MIZIARA, F. Expansão de fronteiras e ocupação do espaço no Cerrado: o caso de Goiás. In: DANIEL, M. A.; DAL'LARA, L.; ANACLETO, T. C. S. (Orgs.). Natureza viva Cerrado. Goiânia: Ed. da UCG, 2005. p. 169-196.

OLIVEIRA, A. U. A agricultura camponesa no Brasil. 3. ed. São Paulo: Contexto, 1997.

PASQUALETTO, A.; ZITO, R. Impactos ambientais da monocultura da cana-de-açúcar. Goiânia: Ed. da UFG, 2000.

REPÓRTER BRASIL. O zoneamento agroecológico da cana-de-açúcar: análise dos avanços e das lacunas do projeto oficial. 2009. Disponível em: $<$ www.reporterbrasil. org.br>. Acesso em: 13 out. 2009.

SANTOS, M. H. M. C. A expansão canavieira em Goiás e seus reflexos: exemplo de Santa Helena de Goiás (tratamento gráfico da informação). 1987. 174 f. Dissertação (Mestrado em Geografia)-Faculdade de Filosofia, Letras e Ciências Humanas, Universidade de São Paulo, 1987.

UNIÃO DA INDÚSTRIA DE CANA-DE-AÇÚCAR (Unica). Produção e uso do etanol combustível no Brasil. São Paulo: Unica, 2007.

UNIVERSIDADE ESTADUAL DE CAMPINAS (Unicamp). Núcleo Interdisciplinar de Planejamento Energético. Estudo sobre as possibilidades e impactos da produção de grandes quantidades de etanol visando à substituição parcial de gasolina no mundo: relatório final. Campinas: Unicamp, 2005.

VELHO, O. G. Frentes de expansão e estrutura agrária: estudos do processo de penetração numa área da Transamazônica. Rio de Janeiro: Zahar, 1972.

WORLD WILDLIFE FUND (WWF). Expansão agrícola e perda da biodiversidade no Cerrado: origens históricas e o papel do comércio internacional. Brasília, DF: WWF Brasil, 2000. 